\title{
PEMANFAATAN TEKNOLOGI INFORMASI DAN KOMUNIKASI (TIK) DALAM MENINGKATAN MUTU PERGURUAN TINGGI AGAMA HINDU
}

\author{
Oleh \\ I Gede Agus Krisna Warmayana \\ Institut Hindu Dharma Negeri Denpasar \\ aguskrisna@ihdn.ac.id
}

Diterima 24 Juli 2018, direvisi 26 Juli 2018, diterbitkan 31 Agustus 2018

\begin{abstract}
Information and Communication Technology (ICT) is a fundamental requirenment in Education. ICT plays an important role in improving the quality of higher education. In improving the quality of higher education, especially Hindus-based colleges, a management model of academic service management is needed in terms of policy makers, planners, organizers, implementers, and controlling the quality of academic services. The data was collected throughout observation, interviews, and document analysis. Particularly for data analysis, an interactive model was used including data collection, data reduction, data display, and conclusions. The results of this study indicated that the application of quality management of ICT-based academic services is highly effective in higher education because of policy documents and quality control instrumentation which resulted on an optimal and fast service processes, easy coordination and integration between many ICT-based academic service institutions, academic information system database (SIAKAD) and PDDIKTI, a qualified control institutions specifically in aspects of institutional structure, human resources, and quality instrumentation; and there is a commitment from all steakholder owners to implement a quality and ICT-based culture.
\end{abstract}

\section{Keywords: ITC, management model, SIAKAD.}

\section{PENDAHULUAN}

Teknologi informasi dan komunikasi (TIK) dizaman sekarang menjadi suatu kebutuhan mendasar dalam sebuah orginasasi, perusahaan, instansi pemerintah dan instansi pendidikan. Peranan TIK dalam dunia Pendidikan merupakan sebagai gudang ilmu pengentahuan, alat bantu pembelajaran, standar kompetensi, penunjang administrasi Pendidikan, alat bantu manajemen Pendidikan. Dalam renstra Depdiknas penempatan TIK menjadi bagian yang penting upaya peningkatan mutu. 
Beberapa penelitian tentang pemanfaatan TIK dalam peningkatan mutu layanan akademik menunjukkan bahwa (Taiwan School Cyberfair 2008: 52) :

1. Persepsi mahasiswa tentang kualitas layanan akademik berkorelasi dengan persepsi mereka tentang kualitas pembelajaran.

2. Pembelajaran yang dirasakan para mahasiswa, secara konstruk merupakan bagian dari kualitas layanan dan dapat juga keduanya saling tumpang tindih.

3. Berbeda dengan konstruk pembelajaran, beberapa konstruk bahwa dengan pemanfaatan ICT telah mampu meningkatkan motivasi belajar para peserta didik.

Ada beberapa literatur pemanfaatan TIK dalam dunia Pendidikan:

1. Pengelolaan Sistem Informasi Akademik Perguruan Tinggi Berbasis Teknologi Informasi Dan Komunikasi (TIK) oleh Etin Indrayani tahun 2011 hasilnya secara simultan memberikan pengaruh yang signifikan dan memiliki sumbangan yang sangat besar terhadap kinerja lembaga dan Efektivitas sistem dan budaya organisasi tidak memiliki sumbangan yang signifikan terhadap kinerja lembaga

2. Manajemen Mutu Layanan Akademik Berbasis Teknologi Informasi Dan Komunikasi (TIK) oleh Ali Idrus tahun 2014 hasilnya untuk memperoleh data empiris tentang keadaan faktor-faktor yang terkait dengan pengelolaan Sistem Informasi Akademik berbasis TIK terhadap kinerja sekolah dan dampaknya terhadap prestasi akademik siswa

3. Penjaminan Mutu Pendidikan Melalui Teknologi Informasi Di Institut Hindu Dharma Negeri Denpasar oleh I Gusti Ngurah Triyana tahun 2017 hasilnya penerapa teknologi informasi untuk menjamin mutu di Institut Hindu Dharma Negeri (IHDN) Denpasar
4. Manajemen Mutu Layanan Akademik Berbasis Teknologi Informasi Dan Komunikasi (TIK) Di Perguruan Tinggi Agama Islam oleh Imam Makruf tahun 2018 hasilnya kurang efektifenya manajemen mutu layanan akademik berbasis TIK di PTAIN dengan model studi kasus di IAIN Surakarta dan STAIN Salatiga.

Dari beberapa penelitian diatas di perguruan tinggi Agama Hindu belum ada pembahasan mengenai Pemanfaatan Teknologi Informasi Dan Komunikasi (TIK) Dalam Meningkatan Mutu Perguruan Tinggi terkait dengan kebijakan, setidaknya ada 3 (tiga) hal yang perlu dikaji dalam pembahasan ini, yaitu proses perumusan kebijakan, dokumen kebijakan, dan program implementasi kebijakan.

\section{PEMBAHASAN}

Pemanfaatan Teknologi Informasi Dan Komunikasi (TIK) Dalam Meningkatan Mutu Perguruan Tinggi Agama Hindu ada 3 (tiga) hal yang perlu dikaji dalam pembahasan ini, yaitu proses perumusan kebijakan, dokumen kebijakan, dan program implementasi kebijakan.

a. Proses Perumusan Kebijakan

Proses perumusan kebijakan terkait erat dengan proses pengambilan keputusan. Proses pengambilan keputusan merupakan aktivitas fundamental dalam organisasi. Terdapat empat metode pengambilan keputusan, yaitu kewenangan tanpa diskusi (authority rule without discussion), pendapat ahli (expert opinion), kewenangan setelah diskusi (authority rule after discussion), dan kesepakatan (consensus).

Dalam kaitannya dengan penelitian ini, proses pengambilan kebijakan yang dilakukan oleh pimpinan perguruan tinggi metode yang bisa digunakan empat metode untuk menghasilkan kebijakan yang akuntabel. Proses ini dilakukan dengan cara membawa kebijakan yang akan dirumuskan ke forum senat perguruan tinggi untuk mendapatkan persetujuan dan ke forum workshop untuk 
merumuskan dokumen kebijakannya. Rumusan berasal dari visi-misi dan tujuan dari perguruan tinggi yang diterjemahkan oleh pejabat saat itu. Namun demikian untuk melandaskan kebijakan yang akan dikuatkan dengan keputusan Rektor maupun Ketua perguruan tinggi, membutuhkan masukan dan legalitas dari forum senat kampus. Di sinilah terjadi pembahasan atau diskusi secara intens.

Hal yang menjadi kekuatan terhadap adanya kebijakan Pemanfaatan Teknologi Informasi Dan Komunikasi (TIK) Dalam Meningkatan Mutu Perguruan Tinggi Agama Hindu adalah dikeluarkannya Peraturan Rektor atau Ketua perguruan tinggi. Hal ini menjadi sangat urgen karena dengan terbitnya peraturan tersebut, menuntut adalah langkahlangkah atau program-program yang jelas dan sistematis agar implementasinya dapat lebih terjamin. Misalnya, dengan adanya peraturan Rektor atau ketua tersebut kemudian ditindaklanjuti dengan adanya program pengembangan infrastruktur seperti pengembangan aplikasi program sistem akademik, pengembangan data center, pembangunan gedung laboratorium terpadu, pengembangan jaringan hotspot area peningkatan kompetensi SDM dan sebagainya.

b. Dokumen Kebijakan Manajemen Mutu Layanan Akademik

Kebijakan pengembangan sistem layanan akademik di Perguruan Tinggi Agama Hindu sudah berjalan, tetapi dokumen dan konsideran kebijakan belum tertata dengan baik. Bahkan untuk mendapatkan dokumen kebijakan tersebut masih cukup sulit karena belum terdokumentasi dan terkodifikasi dalam satu dokumen. Ada 7 (tujuh) jenis dokumen kebijakan manajemen mutu yang perlu, yaitu:

1. Sistem Penyelenggaraan Pendidikan.

2. Standar Kompetensi Lulusan

3. Rencana Strategis perguruan tinggi

4. Kebijakan mutu perguruan tinggi

5. Pedoman Prosedur Perkuliahan
6. Pedoman prosedur penggunaan aplikasi

7. Buku-buku pedoman terkait penyelenggaraan akademik.

c. Program yang mendukung implementasi kebijakan

Untuk mengimplementasikan sebuah kebijakan harus didukung dengan program-program yang tepat. Untuk Pemanfaatan Teknologi Informasi Dan Komunikasi (TIK) Dalam Meningkatan Mutu Perguruan Tinggi Agama Hindu, maka program-program yang diimplementasikan adalah; pengembangan kelembagaan, pengembangan infrastruktur atau sarana prasarana, dan pengembangan SDM.

1. Pengembangan Kelembagaan

Pengembangan kelembagaan yang terjadi di Perguruan Tinggi antara lain adalah;

(a) Perubahan dari Sekolah Tinggi menjadi Institut atau institute menjadi universitas,

(b) Perubahan dari UPT Pusat Komputer menjadi PTIPD

2. Pengembangan Infrastruktur TIK Ada beberapa jenis sarana prasarana yang dapat dikatakan ideal yaitu; gedung laboratorium, perpustakaan, kantor, data center, dan jaringan wifi yang sudah mampu menjangkau semua area di kampus, sistem aplikasi akademik, e-learning, e-library, ejournal dan sms akademik.

3. Kompetensi SDM

Perguruan Tinggi Agama Hindu harus perhatian terhadap kompetensi SDM baik dari unsur tenaga pendidik maupun tenaga kependidikan. kepedulian lembaga terhadap upaya untuk meningkatkan kualitas SDM. Misalnya pelatihan-pelatihan diberikan kepada para tenaga kependidikan dalam pemanfaatan teknologi informasi secara umum maupun untuk mengaplikasikan program-program khusus, seperti pelatihan atau workshop Education 
Management Information System (EMIS). Di samping itu juga workshop dan pelatihan-pelatihan teknis terkait dengan penggunakan sistem akademik untuk sistem layanan akademik, penggunaan SIMKEU untuk sistem administrasi keuangan, SIMPEG, SIEKA untuk sistem administrasi kepegawaian, PDDIKTI untuk pengelolaan database lembaga pendidikan, pelatihan e-journal dan sebagainya.

Perguruan Tinggi harus memiliki kualitas tenaga akademik yang dimiliki cukup kompeten dan mampu mengikuti tuntutan kinerja yang dikembangkan. Indikator lain yang menunjukkan kompetensi staf akademik adalah, bahwa mereka mampu mengerjakan tugas-tugas terkait layanan akademik tepat waktu, seperti dalam hal melakukan validasi data, cetak transkrip akademik, pencetakan presensi perkuliahan, monitoring pelaksanaan kegiatan akademik, dan lain-lain.

Di tingkatan dosen harus menguasi teknologi informasi yang dapat dilaksanan dalam tri dharma perguruan tinggi seperti dalam bidang pengajaran berbasis IT, penelitian maupun bidang yang lainnya

Adapun untuk meningkatkan SDM dalam penggunan IT memberikan pelatihan penggunaan sistem akademik untuk para dosen, memberikan penegasan terkait dengan tugas pokok dan fungsi dosen terkait administrasi akademik yang tidak boleh diwakilkan kepada orang lain melalui rapat evaluasi pembelajaran di akhir semester ataupun menggunakan surat edaran yang ditandatangani dekan. Untuk kekurangan dosen, dibutuhkan kebijakan khusus tentang pengangkatan dosen tidak tetap dengan pedoman prosedurnya.
Penelitian dari Mercedes MarzoNavarro, dkk (2005: 35), bahwa kepuasan pelanggan dipengaruhi oleh kompetensi SDM, maka dimungkinkan bahwa pelanggan dari Perguruan Tinggi Agama Hindu yang menerapkan layanan akademik berbasis TIK ini akan belum mampu tercapai secara optimal.

2. Perencanaan Mutu Layanan Akademik Berbasis TIK

Terkait dengan pengembangan desain sistem informasi di perguruan tinggi agama harus dibuat blue print atau masterplan yang menggambarkan grand design dari sistem teknologi informasi di perguruan tinggi secara keseluruhan. Blue print dibuat untuk masa lima tahunan. Dari dokumen masterplan tersebut nampak dengan jelas arah perencanaan pengembangan sistem informasi dan teknologi yang akan diwujudkan. Inti dari grand design tersebut adalah diarahkan pada upaya untuk mewujudkan digitalisasi semua aspek layanan akademik dan non akademik. Perguruan tinggi agama hindu akan dibawa ke arah kampus yang modern berkelas internasional. TIK dalam hal ini merupakan ujung tombak yang dikembangkan untuk mewujudkan kampus modern.

\section{Pengorganisasian Mutu Layanan} Akademik Berbasis TIK

Secara kelembagaan, mutu layanan akademik di Perguruan Tinggi Agama Hindu ditangani oleh Pusat Teknologi Informasi dan Pangkalan Data (PTIPD) yang langsung bertanggungjawab kepada Rektor/Ketua melalui Wakil Rektor/ Wakil Ketua. PTIPD ini secara struktural masuk dalam organisasi dan tata kerja (ortaker) dan Statuta Perguruan Tinggi. Sebelumnya lembaga ini bernama UPT Pusat 
Komputer. Perubahan nama ini tidak lepas dari adanya kebijakan dari Direktorat Diktis Kemenag RI.

Dalam pelaksanaan tugasnya, PTIPD atau UTIPD tidak bekerja sendirian, tetapi melibatkan para staff akademik yang bertugas sebagai operator SIAKAD atau operator sistem informasi lainnya. Para staff akademik tersebut ada di tingkat institut maupun fakultas dan pascasarjana. Pola hubungan antara PTIPD dengan bagian akademik di institut maupun fakultas adalah pola koordinatif, bukan jalur instruktif. Hal ini berbeda dengan pola hubungan antara penanggungjawab akademik di tingkat institut yaitu Wakil Rektor I beserta Kepala Biro dan Kabag Akademik dengan pelaksana akademik di tingkat fakultas yaitu Wakil Dekan I, Kabag TU, dan Kasubag Akademik yang memiliki jalur instruksi.

4. Efektifitas Implementasi Layanan Akademik Berbasis TIK

Pelaksanaan layanan akademik berbasis TIK secara garis besar dapat dikelompokkan menjadi dua, yaitu layanan kepada mahasiswa dan layanan kepada dosen. Kedua kelompok tersebut sama-sama mendapatkan layanan akademik yang berupa layanan administrasi akademik dan pendukung akademik / perkuliahan. Sistem layanan yang digunakan untuk administrasi akademik adalah menggunakan sistem informasi administrasi akademik (SIAKAD) dan layanan pendukung akademik dengan layanan digital library.

a. Layanan untuk mahasiswa

Layanan akademik kepada mahasiswa dilakukan semenjak mahasiswa mendaftar untuk masuk di kampus sampai mereka lulus, yaitu sejak proses penerimaan mahasiswa baru yang dilakukan secara online, kemudian proses registrasi online, pengambilan mata kuliah dan pengisian KRS, pencetakan KHS dan transkrip akademik, serta proses ujian-ujian. Dalam proses layanan ini, ada yang dilakukan langsung oleh mahasiswa, yaitu;

- Registrasi.

- Pengisian dan pencetakan KRS.

- Membuka dan mendownload SAP atau bahan ajar.

- Melihat nilai dari mata kuliah atau praktikum.

Layanan akademik untuk mahasiswa yang dalam praktiknya dilakukan oleh dosen antara lain:

- Mengecek jadwal perkuliahan dan jadwal ujian.

- Melakukan Acc pada KRS secara online di SIAKAD.

- Upload SAP atau bahan ajar ke SIAKAD.

- Menginput daftar hadir mahasiswa dan mengisi jurnal perkuliahan.

- Menginput nilai ke dalam form nilai di SIAKAD.

Layanan akademik untuk mahasiswa yang dalam praktiknya dilakukan oleh staff akademik antara lain:

- Menyusun, mencetak, dan mendistribusikan jadwal perkuliahan.

- Mencetak daftar hadir mahasiswa beserta form jurnal perkuliahan.

- Menyiapkan dan mencetak Kartu Ujian.

- Menyiapkan dan mencetak KHS dan Transkrip Akademik.

- Mengupload berbagai pengumuman akademik di SIAKAD

- Memberikan layanan pembuatan User Id dan Password.

b. Layanan untuk dosen

Bentuk-bentuk layanan akademik dengan SIAKAD yang harus dilakukan sendiri oleh dosen adalah:

- Mengecek jadwal perkuliahan dan jadwal.

- Upload SAP atau bahan ajar ke SIAKAD.

- Mencetak daftar hadir mahasiswa dan jurnal perkuliahan pada akhir 
semester untuk kebutuhan bukti fisik LBKD dan SKP.

Memanfaatkan SIAKAD untuk menginput nilai selama proses pembelajaran dan diupload tepat waktu serta mencetaknya untuk kebutuhan laporan BKD dan SKP.

Mengecek progres dari semua mahasiswa bimbingannya (perwaliannya).

Sedangkan bentuk-bentuk layanan akademik untuk dosen yang dilakukan oleh staff akademik antara lain:

- Menyusun jadwal perkuliahan di awal semester.

- Menyiapkan dan mencetak daftar hadir mahasiswa beserta form jurnal perkuliahan untuk setiap mata kuliah dan program studi.

Menyiapkan dan mencetak daftar hadir dosen mengajar.

- Menyiapkan dan mencetak KHS dan Transkrip Akademik dan diserahkan ke dosen PA sebagai arsip.

- Memberikan layanan untuk mendapatkan User Id dan Password.

Pelaksanaan layanan akademik berbasis TIK juga diberikan dalam bentuk layanan elearning, ejournal, e-Conference, digital library yang terintegrasi dengan layanan perpustakaan secara menyeluruh. Layanan yang dapat dilakukan dari mana saja, adalah terkait dengan akses digital library yang diakses melalui website perguruan tinggi masing-masing. Sedangkan yang hanya dapat diakses melalui anjungan yang ada di perpustakaan adalah terkait dengan akses database dan katalog khusus yang hanya disiapkan dengan sistem akses menggunakan Lokal Area Network (LAN).

Secara organisatoris, tanggungjawab pelaksanaan sistem layanan akademik tersebut ada di tangan para pejabat di tingkat jurusan, fakultas dan institut yang terkait langsung dengan bidang akademik. Dalam hal ini, jika di Universitas atau insitut terdiri atas Wakil Rektor I, Wakil Dekan I, Kabag Akademik dan Kasubag Akademik di tingkat Institut, serta Kabag TU dan Kasubag Akademik di tingkat fakultas. Sedangkan untuk di Sekolah Tinggi, terdiri atas Wakil Ketua I, Kabag TU, beserta Kasubag Akademik.

Hasil penelitian Hasbullah dan Maman Sumantri (2009) menyatakan bahwa semua faktor dalam terkait pembelajaran akan mempengaruhi keberhasilan pengembanan $e$ learning. Artinya, sistem harus disiapkan secara baik, SDM harus dilatih agar benarbenar berkompeten, dan layanan harus diberikan secara maksimal dengan berorientasi pada kepuasan pelanggan. Dengan demikian proses implementasi layanan akademik berbasis TIK bisa efektif.

4. Mekanisme Pengendalian Mutu Layanan Akademik Berbasis TIK

Sistem monitoring dan evaluasi mutu layanan akademik secara kelembagaan menjadi satu kesatuan proses dari penyelenggaraan pendidikan di perguruan tinggi. Di lembaga Perguruan Tinggi secara kelembagaan telah ditetapkan adanya LPM untuk Universitas atau institut dan UPMA untuk Sekolah Tinggi . Untuk LPM di Universitas/ Institut dalam menjalankan tugasnya dibantu oleh Sekretaris dan dua kepala pusat, yaitu Pusat Pengembangan Standar Mutu, Pusat Audit dan Pengendalian Mutu. Khusus proses monitoring dan evaluasi dilakukan oleh Pusat Audit dan Pengendalian Mutu. Sedangkan di Sekolah Tinggi, pelaksana tugas adalah langsung kepala UPMA dibantu oleh seorang Sekretaris. Dalam melaksanakan tugastugasnya melibatkan beberapa unsur mulai dari tingkat rektorat sampai dengan fakultas tetapi tetap di bawah kendali LPM.

Proses pengendalian mutu harus terpola dengan mekanissme yang baik. Proses pengendalian mutu ada beberapa hal ditekanan:

a. Secara kelembagaan LPM masih harus mapan

b. Secara dokumen, berbagai instrumen yang digunakan untuk melakukan assessment sudah tersedia secara lengkap.

c. Mekanisme pengendalian yang terintegrasi dalam sistem dapat dijalankan secara optimal. 
d. Budaya mutu menjadi orientasi kinerja para dosen dan staff secara menyeluruh.

Ruang lingkup dan proses monitoring dan evaluasi secara garis besar dilakukan dalam dua bentuk. Pertama monitoring terhadap pelaksanaan layanan akademik secara menyeluruh yang dilakukan oleh pihakpihak terkait seperti oleh pejabat dan penanggungjawab akademik, dosen, dan staff akademik. Kedua monitoring terhadap penggunaan SIAKAD dengan cara melakukan monitoring terhadap pemanfaatan fitur-fitur yang ada dalam SIAKAD sesuai dengan kalender akademik. Dalam proses ke dua ini monitoring melibatkan team penanggungjawab TIK beserta operator baik yang ada di tingkat institut maupun di tingkat fakultas. Dengan demikian data-data diperoleh dari para operator yang kemudian dioleh oleh LPM atau UPMA.

Sebagaimana tugas pokok dan fungsi dari LPM atau UPMA, semua hasil dari monitoring dan evaluasi terhadap implementasi sistem layanan akademik tersebut kemudian dilaporkan kepada pejabat yang berwenang, seperti Wakil Rektor I dan para dekan untuk ditindak lanjuti. Mekanisme harus berjalan secara maksimal. PTIPD sebagai penanggungjawab implementasi TIK termasuk di dalamnya SIAKAD melakukan evaluasi sendiri yang kemudian dilaporkan kepada Rektor melalui Wakil Rektor I Bidang Akademik. Di lingkungan fakultas, monitoring dilakukan oleh dekan yang dalam hal ini dilaksanakan oleh Wakil Dekan I bidang Akademik dengan melibatkan Kabag TU, Kasubag Akademik, dan para operator SIAKAD di fakultas. Hasilnya langsung ditindak lanjuti oleh masing-masing fakultas.

Proses monitoring dan evaluasi yang dilakukan secara terintegrasi dan terkoordinasi langsung dari LPM, tidak boleh dilakukan secara parsial di setiap leading sector. Fungsi audit internal yang harus berjalan secara efektif.

Meskipun demikian, jika merujuk kembali pada pendapat dari Westerheijden et al. (2007: 156) bahwa "quality assurance as a policy domain" dan pendapat David Lim (2001) yang menyatakan bahwa penjaminan mutu terkait dengan semua kebijakan dan proses yang diarahkan untuk menjamin pemeliharaan dan peningkatan mutu institusi.

Penjaminan mutu harus meliputi proses pengambilan kebijakan, proses penyusunan perencanaan, proses pengorganisasian, dan proses pelaksanaan atau implementasi yang bebasis TIK. Proses ini dilakukan berdasarkan visi, misi, tujuan serta renstra perguruan tinggi yang bermanfaat untuk meningkat akreditasi prodi maupun institusi.

\section{SIMPULAN}

Pemanfaatan Teknologi Informasi Dan Komunikasi (TIK) Dalam Meningkatan Mutu Perguruan Tinggi Agama Hindu

ada 3 (tiga) hal yang perlu diefektifkan yaitu:

1. Proses perumusan kebijakan yang dirumuskan oleh perguruan tinggi terkait dengan implementasi manajemen mutu layanan akademik berbasis TIK dirumuskan secara baik dan sesuai kebutuhan stakeholder, diwujudkan dengan berbagai program yang strategis

2. Dokumen kebijakan Proses, dalam perencanaan manajemen mutu layanan akademik berbasis TIK dengan baik dan komprehensif dengan melibatkan unsur terkait secara proporsional kemudian didokumentasi secara baik.

3. Program implementasi kebijakan.

Proses implementasi mutu layanan akademik berbasis TIK melibatkan unsur-unsur yang terkait, memiliki database benar-benar valid dan system terintegrasi antara SIAKAD dengan PDDIKTI, serta kuatnya dalam penciptaan budaya mutu yang berkomitmen dari semua steakholder.

Penjaminan mutu secara menyeluruh mulai dari pengambilan kebijakan, perencanaan, pengorganisasian, sampai pelakanaannya. Untuk itu upaya penguatan LPM berbasis TIK menjadi prioritas agar mampu melakukan pengendalian mutu secara optimal ditandai dengan naiknya peringkat akreditasi program studi dan akreditasi institusi. 


\section{DAFTAR PUSTAKA}

Hasbullah dan Sumantri, M. (2009). Pengembangan Model Pembelajaran ELearning Untuk Meningkatkan Kualitas Proses dan Hasil Belajar Mahasiswa pada Mata Kuliah Energi dan Konversi.Jurnal Penelitian., 10 (2).Oktober 2009.

Indrayani, O. E., Ipdn, D., Mahasiswa, S., \& Upi, A. (2011). BERBASIS TEKNOLOGI INFORMASI DAN KOMUNIKASI ( TIK ) Jurnal Penelitian Pendidikan Pemanfaatan Teknologi Informasi dan TIK dalam proses pengelolaan kelembagaan ini baik faktor teknis maupun non teknis . pada meningkatnya kinerja lembaga pendidikan tinggi da. Jurnal Penelitian Pendidikan, 12(1), 45-60.

Lim, D. (2001). Quality Assurance in Higher Education. Sydney: Ashgate.

Makruf, I. (2018). Manajemen mutu layanan akademik berbasis teknologi informasi dan komunikasi (tik). Jurnal Administrasi Pendidikan, (1), 129-139.

Marzo-Navarro, M. dkk, (2005). Measuring customer satisfaction in summer courses.Jurnal Quality Assurance in Education. 13 (1).hlm. 53-65.

Triyana, I. G. N. (2017). PENJAMINAN MUTU PENDIDIKAN MELALUI TEKNOLOGI INFORMASI DI INSTITUT HINDU DHARMA NEGERI DENPASAR. Jurnal Penjaminan Mutu, 3(1), 119-126.

Westerheijden, D. F. et al. (2007). Quality Assurance in Higher Education. Dordrecht: Springer

Young, S. S.-C., and Ku, H-H. (2008). "A study of uses of ICT in primary education through four winning school cases in the Taiwan Schools Cyberfair. (Information Communication Technology)(Report). Educational Technology and Society Journal.11 (3), hlm.52-67. 